\title{
Total Phenolic Content and Antioxidant Activity of Two Teucrium Species from Syria
}

\author{
Reem Ghassan Alali* and Mays Rizk Khazem
}

\author{
Department of Pharmacognosy, Faculty of Pharmacy, Damascus University, Damascus, Syria
}

\begin{abstract}
Germander (Teucrium, Lamiaceae) is a genus commonly used as a medicinal herb in the middle east. The aim of this study was to estimate total polyphenols and antioxidant activity of different extracts from two Syrian Teucrium species (Teucrium polium and Teucrium creticum). Total polyphenols content was measured using Folin-Ciocalteu assay and the antioxidant activity was evaluated in vitro by DPPH assay (free radical scavenging activity against 1, 1diphenyl-2-picrylhydrazyl). The total polyphenols content and antioxidant activity of $T$. creticum extracts were higher than T. polium ones. Phenols contents ranged from 16.388 to $105.672 \mathrm{mg} \mathrm{GA} \mathrm{E/} \mathrm{g} \mathrm{dry} \mathrm{weight} \mathrm{extract.} \mathrm{The} \mathrm{extracts} \mathrm{showed}$ significant scavenging activity against DPPH, with IC50 values ranging between 0.195 and $0.710 \mathrm{mg} / \mathrm{ml}$. The methanolic extracts show higher antioxidant activity from the two species. A good correlation between DPPH scavenging activities and contents of polyphenols was found. These results show that Syrian Teucrium species, especially T. creticum least Known among all, is a rich source of phenols and natural antioxidant compounds, that can be used as a natural food preservative.
\end{abstract}

Keywords: Teucrium polium, Teucrium creticum, Germender, Polyphenols, Antioxidant activity.

\section{INTRODUCTION}

During normal metabolism in aerobic cells, molecular oxygen is converted to water, then the stepwise transmit of electrons generates free reactive oxygen species (ROS) [1]. Massive generation of ROS and other radicals can damage important biomolecules such proteins, carbohydrates, fatty acids, and DNA, and may thus carry to oxidative intensity and to variety of degenerative processes and diseases, such as aging, neurologic disorders, inflammation, arteriosclerosis, cardio vascular disease, and certain cancers [2].

Plant phenolics were considered to have antioxidant activities due to their role as reducing agents, hydrogen donor antioxidant and singlet oxygen quenchers [3]. The genus Teucrium (Lamiaceae) contains 300 species spread all over the world, particularly in the Mediterranean basin [4]. In Syria there are more than 14 species. $T$. polium is the most Known and commonly used in folk medicine as an antigastrointestinal colic. It is named "Jaada" and "Quaisa".

Meanwhile searching in the literature, numerous studies demonstrated anti-inflammatory [5], antibacterial [6], antiulcer [7], anti-nociceptive [8], antipyretic [9], hypolipidemic [10], hypoglycemic [11] effects of $T$. polium, as well as found to be used for treatment of hypertensive and intestinal troubles [12].

*Address correspondence to this author at the Department of Pharmacognosy, Faculty of Pharmacy, Damascus University, Damascus, Syria;

Tel: 0963996199365; E-mail: reemali2542019@gmail.com

ISSN: 2223-3806 / E-ISSN: 1927-5951/20
These therapeutic benefits of $T$. polium extracts are usually attributed to their ability to suppress oxidative process [13]. In this study, we aimed to highlight a new species of Teucrium ( $T$. creticum) spread in Syria, which has not been studied yet, and compare their total poly phenols content and antioxidant activity with those of $T$. polium.

\section{MATERIALS AND METHODS}

\section{Reagents and Standards}

2,2-Diphenylpicryl hydroxyl radical (DPPH) and Folin-Ciocalteu were purchased from Sigma Aldrich, vitamin $\mathrm{C}$ and gallic acid from Prolabo, and sodium carbonate.

Solvents: chloroform, ethyl acetate and methanol were purchased from Surechem products LTD (SCP) with distillation range (95\%) and all the other chemicals and solvents used were of analytical grade.

\section{Plant Materials}

Aerial parts of $T$. polium and $T$. creticum were collected from flowering plants in May 2018 from Homs and Lattakia (Syria) respectively. They were identified by Professor Imad Alkadi, Botanist at faculty of sciences, Damascus University, Syria.

\section{Preparation of Teucrium Extracts}

The plant material was dried at room temperature in a dark place, powdered, then extracted by progressive polarity solvents: chloroform, ethyl acetate, methanol 
and water (using $20 \mathrm{~g}$ of the powdered plant with 200 $\mathrm{ml}$ of each solvent). We obtained the chloroform, ethyl acetate, methanol extracts by soxhlet apparatus (continual extraction for 24 hours). Water extract by digestion and ultrasonication method. The resultant extracts were filtered and concentrated under vacuum using Rotary evaporator. The obtained dry extracts were stored in refrigerator at $4^{\circ} \mathrm{C}$.

\section{Statistical Analysis}

All analysis was done triplicate, and values were then presented as average values along with their standard deviations. Data statistical analysis of scavenging activity assay and total phenol were performed by using one- way ANOVA followed by Tuckey-test. The level of significance was set at $p<$ 0.05 .

\section{Determination of Total Phenolic Content}

Total phenolic content of the extract was determined by the Folin-Ciocalteu method [14]. The 1 $\mathrm{ml}$ of known dilution of the extract, $9 \mathrm{ml}$ of distilled water and $1 \mathrm{ml}$ of Folin-Ciocalteu were mixed well for 5 minutes, then added to $10 \mathrm{ml}$ of sodium carbonate solution $7 \%$. The absorbance was read at $760 \mathrm{~nm}$ after 40 minutes of incubation at room temperature in the dark.

Gallic acid was used as a standard for the construction of a calibration curve, by preparing a series of standardized concentrations of gallic acid $(5,10,15,20,25) \mathrm{mg} / 100 \mathrm{ml}$ ethanol $50 \%$ and apply the previously mentioned reaction Figure 1. Total phenolic values were calculated from the calibration curve $Y=$ $0.0433 x+0.0474$ with $R^{2}=0.995$, where $x$ is the absorbance, $y$ is the concentration of gallic acid. The calibration method had been validated $\mathrm{R}^{2}$ (correlation coefficient) $=0.995$, SD (standard definition) $=0.67$, RSD (relative standard definition) $=1.67 \%$, LOQ (limit of quantification) $=13.2365 \mathrm{mg} / \mathrm{l}$, LOD (limit of detection) $=4.3681 \mathrm{mg} / \mathrm{l}$ ). Total phenol contents were expressed as milligrams of gallic acid equivalents per gram dry weight of extract (mg GA E/g DW).

\section{DPPH Radical Scavenging Activity}

The ability of the eight Teucrium extracts to scavenge DPPH free radicals was estimated using the method described by Tekao et al. [15] trusted with suitable modifications from Kumarasamy et al. [16] and vitamin $C$ as a reference. The method is based on the reduction of alcoholic DPPH solution in the presence of hydrogen donating antioxidant $(\mathrm{AH})$ due to the formation of the non-radical from $\mathrm{DPPH}-\mathrm{H}$ by the reaction:

$$
\mathrm{DPPH}^{*}+\mathrm{AH} \rightarrow \mathrm{DPPH}-\mathrm{H}+\mathrm{A}^{*}
$$

The solution of the plant extract was prepared in methanol to get the concentration of $1 \mathrm{mg} / \mathrm{ml}$. Dilutions were made to achieve concentrations of $0.05,0.08$, $0.1,0.2,0.4,0.6,0.8,1 \mathrm{mg} / \mathrm{ml}$. Diluted solutions $(1 \mathrm{ml}$ each) were mixed with $1 \mathrm{ml}$ of DPPH methanolic solution $(80 \mu \mathrm{g} / \mathrm{ml})$. After 30 minutes in darkness at room temperature, the absorbance was recorded at $517 \mathrm{~nm}$. The control samples contained all the reagents except the extract. The percentage inhibition was calculated using equation:

Inhibition $(\%)=100 \times(\mathrm{A}$ of control $-\mathrm{A}$ of sample $) / \mathrm{A}$ of control

Concentrations of extracts required to inhibit radical by $50 \%$ (IC50) values were estimated from the \% inhibition versus concentration sigmoidal curve, using

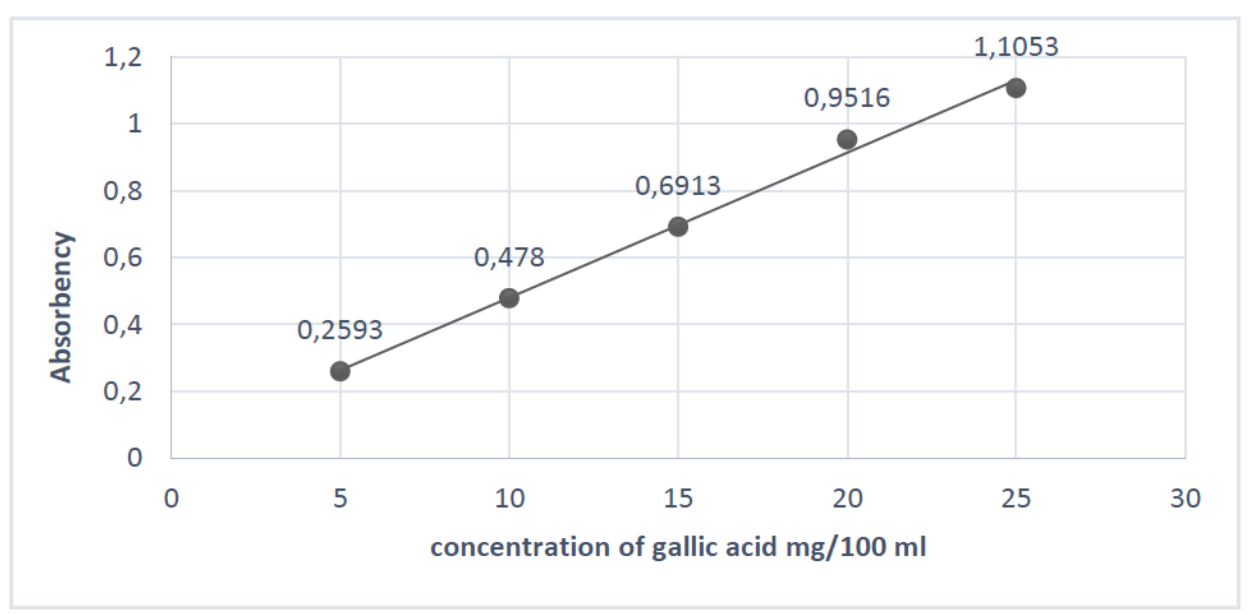

Figure 1: Standard curve of gallic acid. 
Table 1: Extraction Yield of Different T. polium and T. creticum Extracts and TPC Expressed as mg GA E/DWE

\begin{tabular}{|c|c|c|}
\hline TPC (mg GA E/DWE) & Extraction yield (\%) & Type of extracts \\
\hline \hline $32.304 \pm 2.119$ & $24.65 \pm 1.04$ & Water E of $T$. polium \\
\hline $56.038 \pm 3.351$ & $17.75 \pm 1.35$ & Water E of $T$. creticum \\
\hline $82.699 \pm 4.204$ & $14.95 \pm 1.07$ & Methanol E of $T$. polium \\
\hline $105.672 \pm 5.64$ & $14.8 \pm 1.53$ & Ethyl acetate E of $T . p o l i u m$ \\
\hline $35.122 \pm 3.931$ & $4.05 \pm 1.72$ & Ethyl acetate E of $T$. creticum \\
\hline $80.027 \pm 3.930$ & $4.6 \pm 2.1$ & Chloroform E of $T . p o l i u m$ \\
\hline $16.388 \pm 1.388$ & $6.35 \pm 1.09$ & Chloroform E of $T$. creticum \\
\hline
\end{tabular}

Each value expressed as mean of three replicate \pm standard deviation, $E=$ extract.

$(\%)=\mathrm{mg}$ extract $/ 100 \mathrm{~g}$ dry weight plant.

TPC $=$ Total Phenolic Content.

mg GA E/DWE = milligrams of gallic aide equivalence in dry weight extract.

anon-linear regression analysis. The data was presented as mean values \pm standard deviation $(\mathrm{N}=$ $3)$.

\section{RESULTS AND DISCUSSION}

\section{Extraction Yield}

There are a lot of factors that effect the extraction yield like the method of extraction, repetition and time extraction, the solvent used, sample size, presence of overlapping materials as well as chemical nature of the phytochemicals [17]. In this work extraction yield as illustrated in Table 1 ranged from $4.05 \%$ to $24.65 \%$ in T. polium and from $4.6 \%$ to $17.75 \%$ in $T$. creticum, the highest extraction yield is noticed in water and methanol extracts. These results may be due to the higher solubility of proteins, carbohydrates, pigments and other secondary metabolites in polar solvents than nonpolar ones.

\section{Total Phenolic Contents}

The distribution of phenolic content in T. polium and T. creticum is presented in Figure 2 and Table $\mathbf{1}$. The content of total phenolic compounds in extracts, which is expressed as milligrams of gallic acid equivalents per gram of dry weight extract (mg GA E/g DWE), ranged between $16.388 \pm 1.388$ to $105.672 \pm 5.64 \mathrm{mg}$ GA E / g DWE. The results in Figure 2 indicates a significant difference between concentrations of phenol in different solvent extracts. Phenolic contents were the highest in methanol extracts from both plants. Water and ethyl acetate extract also contained high level of phenols, while contents of phenols in chloroform extracts was

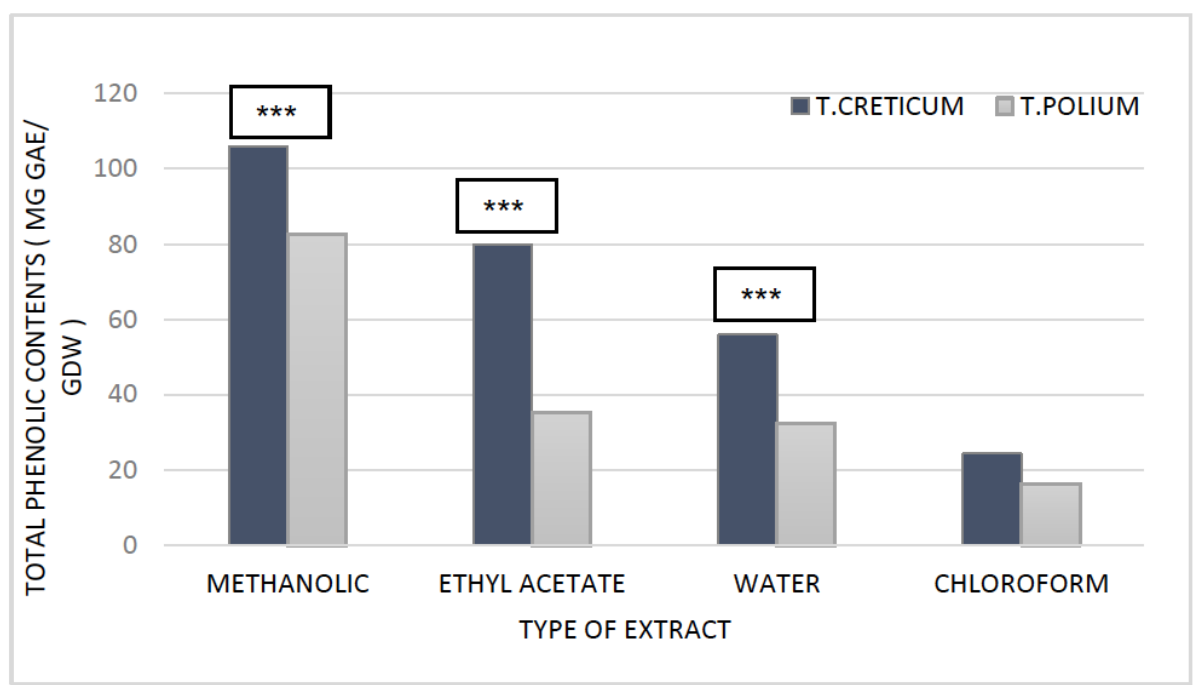

Figure 2: Total phenolic compounds of extracts from T. polium and T. creticum.

Results were expressed as mg GAE/g dry weight. Each value represents means \pm SD of three experiments $\left({ }^{* * *} p<0.05\right)$. 
Table 2: IC50 in DPPH Radical Scavenging Activity $(\mathrm{mg} / \mathrm{ml})$ of $T$. creticum and T. polium Extracts Compared to that of Vitamin C (IC50 = $0.017 \pm 0.0001 \mathrm{mg} / \mathrm{ml})$

\begin{tabular}{|c|c|c|c|c|}
\hline Chloroform & Ethyl acetate & Water & Methanolic & Type of extract \\
\hline $0.52 \pm 0.005$ & $0.33 \pm 0.006$ & $0.20 \pm 0.06$ & $0.19 \pm 0.007$ & Teucrium creticum \\
\hline $0.71 \pm 0.028$ & $0.36 \pm 0.009$ & $0.30 \pm 0.068$ & $0.26 \pm 0.004$ & Teucrium polium \\
\hline
\end{tabular}

Each value expressed as mean of three replicate \pm standard deviation. The extracts of the same solvent and vitamin $C$ are significantly different $(p<0.05)$.

the lower. In all extracts, the Content of phenols was higher in $T$. creticum than $T$. polium. The highest total phenolic concentration is noticed with the methanol extract, this result was in agreement with many previous studies (Y et al. 2019 [18], Stankovic et al. 2012 [19]).

Previous study reported that the variability in the total phenolic contents in different extracts could be the result of many reasons like: varying solubility of the phenolic compounds, method of extraction, the region of the plant, the variation in solubility may be driven by the solvent polarity [20].

\section{Antioxidant Activity}

The antioxidant activity of Teucrium extracts was investigated by the DPPH radical scavenging assay. Results in Table 2 show the IC50 values in DPPH radical scavenging activity assay of $T$. polium and $T$. creticum extracts, the IC50 values of all tested samples ranged from 0.2 to $0.854 \mathrm{mg} / \mathrm{ml}$. The results indicate that $T$. creticum has higher activity than $T$. polium in comparison to the same solvent extract which agree with the high content of poly phenols in $T$. creticum extracts. All extracts show a significant inhibition of the $\mathrm{DPPH}$ radical as follows:

methanol $>$ water $>$ ethyl acetate $>$ chloroform.

The higher activity noticed with polar solvent extracts (methanol and water) may be attributed to the type of polyphenols existed in methanol and water extracts in glycoside form, that may have a larger number of electron-donating hydroxyl groups relative to polyphenols in ethyl acetate and chloroform extracts. Since an antioxidant agent is considered to be active against free radicals if IC50 is less than $5 \mathrm{mg} / \mathrm{ml}$ [21] therefore all our extracts can serve as a strong natural antioxidant.

\section{Correlation of Antioxidant Activity with Phenolic Content}

We found that there was a significant correlation between the total phenolic contents with free radical scavenging activity in methanol, ethylacetate and chloroform extracts $\left(r^{2}=0.7\right)$ for $T$. polium and $\left(r^{2}=0.9\right)$ for $T$. creticum. The free radical scavenging activity against DPPH in our work could be attributed to the phenolics content. According to the previous researches, phenol compounds are recognized as anticancer, anti- inflammatory, anti-bacterial agents because of their free radical scavenging properties [22]. Likewise, there are many benefits of Teucrium species due to their high phenolic contents and antioxidant activities.

\section{CONCLUSION}

Depending on the results we obtained from this study, $T$. polium and $T$. creticum extracts have a remarkable antioxidant effect due to their important content of polyphenols. Therefore, they could serve as a strong protective agent against free radical associated oxidative damage. To the best of our work, this is the first report comparing the antioxidant activity of two Syrian Teucrium species. From the research, we found that $T$. polium spread in Syria have a lower polyphenol content than the species spread in Serbia [19] and Moroco [18]. Another thing observed was that the $T$. creticum in Syria that was studied for the first time had a higher number of polyphenols and a stronger antioxidant activity than $T$. polium.

\section{ACKNOWLEDGEMENT}

The authors wish to thank Professor Imad Alkadi (faculty of science Damascus university, Syria) for the identification of the plants, and doctor Jala Fandi (faculty of pharmacy Damascus university, Syria) for facilitating our field investigation. This work was supported by grants from Damascus university, faculty of Pharmacy.

\section{CONFLICT OF INTEREST}

There is no conflict of interest.

\section{REFERENCES}

[1] Van Acker SAB, Van Balen GP, Van den Berg D, Bast A, Van der Vijgh WJ. Influence of iron chelation on the 
antioxidant activity of flavonoids. Biochem Pharmacol 1998; 56(8): 935-943.

https://doi.org/10.1016/S0006-2952(98)00102-6

[2] Aruoma OI. Nutrition and health aspects of free radicals and antioxidants. Food Chem Toxicol 1994; 32(7): 671-683. https://doi.org/10.1016/0278-6915(94)90011-6

[3] Rice-Evans CA, Miller NJ, Paganga G. Structure-antioxidant activity relationships of flavonoids and phenolic acids. Free Radic Biol Med 1996; 20(7): 933-956. https://doi.org/10.1016/0891-5849(95)02227-9

[4] Ruiters AK, Tilney PM, Van Vuuren SF, Viljoen AM, Kamatou GPP, Van Wyk B-E. The anatomy, ethnobotany, antimicrobial activity and essential oil composition of southern African species of Teucrium (Lamiaceae). S Afr J Bot 2016; 102: 175-185.

https://doi.org/10.1016/j.sajb.2015.06.008

[5] Rahmouni F, Hamdaoui L, Rebai T. In vivo anti-inflammatory activity of aqueous extract of Teucrium polium against carrageenan-induced inflammation in experimental models. Arch Physiol Biochem 2017; 123(5): 313-321. https://doi.org/10.1080/13813455.2017.1333517

[6] Darabpour E, Motamedi H, Nejad SMS. Antimicrobial properties of Teucrium polium against some clinical pathogens. Asian Pac J Trop Med 2010; 3(2): 124-127. https://doi.org/10.1016/S1995-7645(10)60050-8

[7] Twaij HAA, Albadr AA, Abul-Khail A. Anti-Ulcer Activity of Teucrium polium. Int J Crude Drug Res 1987; 25(2): 125128.

[8] Abdollahi M, Karimpour $H$, Monsef-Esfehani HR. Antinociceptive effects of Teucrium polium L. total extract and essential oil in mouse writhing test. Pharmacol Res 2003; 48(1): 31-35. https://doi.org/10.1016/S1043-6618(03)00059-8

[9] Autore G, Capasso F, De Fusco R, Fasulo MP, Lembo M, Mascolo $\mathrm{N}$, et al. Antipyretic and antibacterial actions of Teucrium polium (L.). Pharmacol Res Commun 1984; 16(1): 21-29.

https://doi.org/10.1016/S0031-6989(84)80101-0

[10] Rasekh $H$, Khoshnood-Mansourkhani M, Kamalinejad M. Hypolipidemic effects of Teucrium polium in rats. Fitoterapia 2001; 72(8): 937-939. https://doi.org/10.1016/S0367-326X(01)00348-3

[11] Gharaibeh MN, Elayan HH, Salhab AS. Hypoglycemic effects of Teucrium polium. J Ethnopharmacol 1988; 24(1): 93-99. https://doi.org/10.1016/0378-8741(88)90139-0

[12] Suleiman MS, Abdul-Ghani AS, Al-Khalil S, Amin R. Effect of Teucrium polium boiled leaf extract on intestinal motility and blood pressure. J Ethnopharmacol 1988; 22(1): 111-116. https://doi.org/10.1016/0378-8741(88)90236-X
[13] Ljubuncic P, Dakwar S, Portnaya I, Cogan U, Azaizeh H, Bomzon A. Aqueous Extracts of Teucrium polium Possess Remarkable Antioxidant Activity In vitro. Evid-Based Complementary Altern Med 2006; 3(3): 329-338. https://doi.org/10.1093/ecam/nel028

[14] Ötles S. Methods of Analysis of Food Components and Additives. Chemical \& Functional Properties of Food Components. 3rd ed. Boka Raton: CRC Press 2005. https://doi.org/10.1201/9780203503751

[15] Takao T, Kitatani F, Watanabe N, Yagi A, Sakata K. A. Simple Screening Method for Antioxidants and Isolation of Several Antioxidants Produced by Marine Bacteria from Fish and Shellfish. Biosci Biotechnol Biochem 1994; 58(10): 17801783. https://doi.org/10.1271/bbb.58.1780

[16] Kumarasamy $Y$, Byres M, Cox PJ, Jaspars M, Nahar L Sarker SD. Screening seeds of some Scottish plants for free radical scavenging activity. Phytother Res 2007; 21(7): 615621.

https://doi.org/10.1002/ptr.2129

[17] Stalikas CD. Extraction, separation, and detection methods for phenolic acids and flavonoids. J Sep Sci 2007; 30(18): 3268-3295.

https://doi.org/10.1002/jssc.200700261

[18] El Atki Y, Aouam I, E Kamari F, Taroq A, Lyoussi B and Abdellaoui A. Antioxidnt activity of two wild Teucrium species from Morocco. Int J Pharm Sci \& Res 2019; 10(6): 27232729.

https://doi.org/10.13040/IJPSR.0975-8232.10(6).2723-29

[19] Stankovic MS. Niciforovic N. Mihailovie V, Topuzovic M and Solujic S. Antioxidant activity, total phenolic content and flavonoids concentrations of different plant parts of Teucrium polium L. subsp. Polium Acta Soc Bot Pol 2012; 81(2): 117122.

https://doi.org/10.5586/asbp.2012.010

[20] Marinova EM, Yanishlieva NV. Antioxidative activity of extracts from selected species of the family Lamiaceae in sunflower oil. Food Chem 1997; 58(3): 245-248. https://doi.org/10.1016/S0308-8146(96)00223-3

[21] Abdillah S, Tambunan RM, Farida Y, Sandhiutami NMD, Dewi RM. Phytochemical screening and antimalarial activity of some plants traditionally used in Indonesia. Asian Pac J Trop Dis 2015; 5(6): 454-457. https://doi.org/10.1016/S2222-1808(15)60814-3

[22] Martelli G, Giacomini D. Antibacterial and antioxidant activities for natural and synthetic dual-active compounds. Eur J Med Chem 2018; 158: 91-105. https://doi.org/10.1016/i.ejmech.2018.09.009 